\title{
Parkes Weber syndrome with lymphedema caused by a somatic KRAS variant
}

\author{
Whitney Eng, ${ }^{1}$ Christopher L. Sudduth, ${ }^{2}$ Dennis J. Konczyk, ${ }^{2}$ Patrick J. Smits, ${ }^{2}$ \\ Amir H. Taghinia, ${ }^{2}$ Steven J. Fishman, ${ }^{3}$ Ahmad Alomari, ${ }^{4}$ Denise M. Adams, ${ }^{1}$ \\ and Arin K. Greene ${ }^{2}$
${ }^{1}$ Division of Hematology and Oncology, ${ }^{2}$ Department of Plastic and Oral Surgery, ${ }^{3}$ Department of Surgery, ${ }^{4}$ Department of Radiology, Department of Surgery, Boston Children's Hospital, Harvard Medical School, \\ Boston, Massachusetts 02115, USA
}

Abstract Parkes Weber syndrome is a vascular malformation overgrowth condition typically involving the legs. Its main features are diffuse arteriovenous fistulas and enlargement of the limb. The condition has been associated with pathogenic germline variants in RASA1 and EPHB4. We report two individuals with Parkes Weber syndrome of the leg and primary lymphedema containing a somatic KRAS variant (NM_004985.5:c.35G > A; p.Gly12Asp). KRAS variants, which cause somatic intracranial and extracranial arteriovenous malformations, also result in Parkes Weber syndrome with lymphatic malformations.

Corresponding author: Arin.greene@childrens harvard.edu

(c) 2021 Eng et al. This article is distributed under the terms of the Creative Commons Attribution-NonCommercial License, which permits reuse and redistribution, except for commercial purposes, provided that the original author and source are credited.

Ontology terms: peripheral arteriovenous fistula; predominantly lower limb lymphedema

Published by Cold Spring Harbor Laboratory Press

doi:10.1101/mcs.a006118

\section{INTRODUCTION}

Parkes Weber syndrome is a fast-flow vascular malformation overgrowth condition (Revencu et al. 2008). Its main features consist of diffuse arteriovenous fistulas throughout an extremity, capillary malformation, and limb overgrowth. Arteriovenous shunting can cause a warm limb and congestive heart failure. Treatment includes embolization, excision of overgrown soft tissues, and amputation. Two causes of Parkes Weber syndrome have been identified: germline variants in RASA1 (CM-AVM1) (Revencu et al. 2008) and germline variants in EPHB4 (CM-AVM2) (Amyere et al. 2017). Recently a somatic variant in RASA1 has been shown to cause the condition as well (Flores Daboub et al. 2020).

\section{CASE PRESENTATION}

Two unrelated male patients referred to our Vascular Anomalies Center were diagnosed with Parkes Weber syndrome by physical examination, magnetic resonance imaging (MRI), and angiography (Fig. 1). Both subjects had significant left leg enlargement, edema, lymphorrhea, faint cutaneous vascular stains, and repeated infections requiring hospitalization and antibiotic therapy. Neither individual had baseline cardiac overload or a family history of capillary or arteriovenous malformations. Imaging demonstrated diffuse arteriovenous fistulas throughout the leg, subcutaneous microcystic lymphatic anomalies, and lymphedema. Both individuals were negative for germline RASA 1 variants (data not shown) and had overgrown skin and subcutaneous tissue excised to reduce the size of their limb. 
A

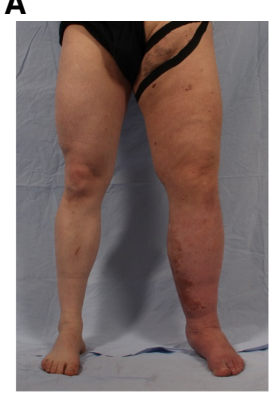

$\mathbf{F}$

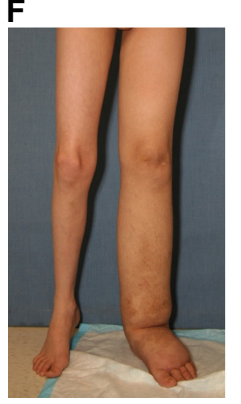

B

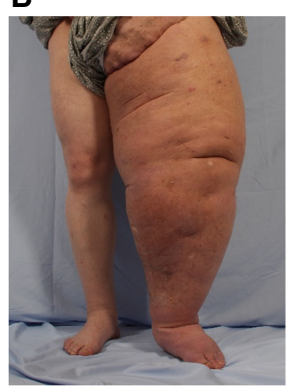

G

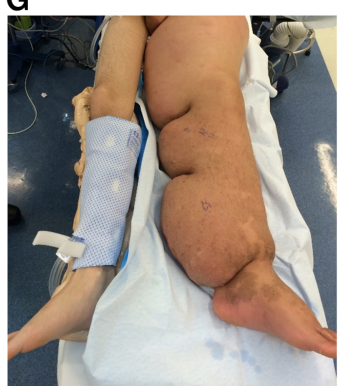

C

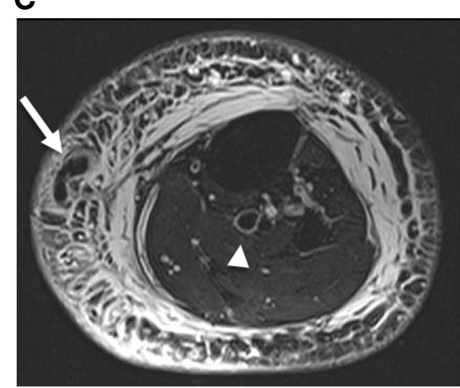

H

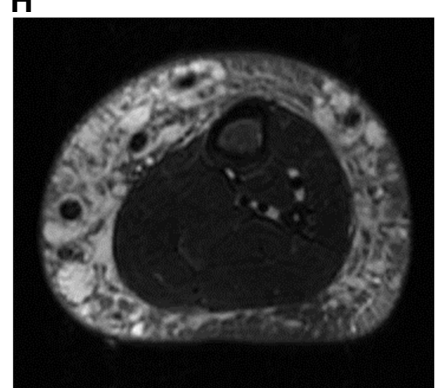

D

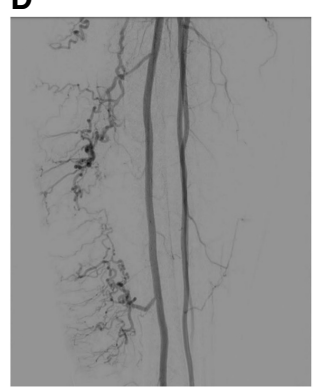

I

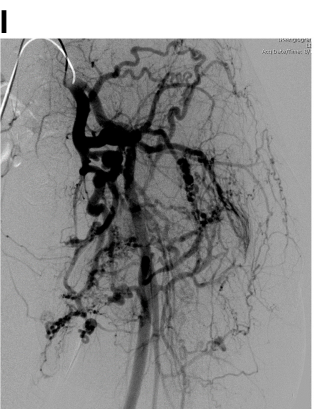

E

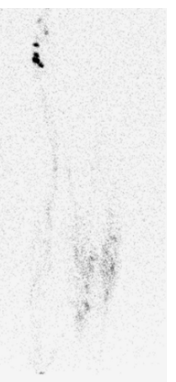

J

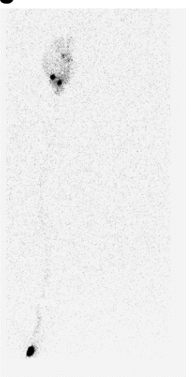

Figure 1. Parkes Weber syndrome with lymphedema caused by a somatic KRAS (NM_004985.5:c.35G > A; p.Gly12Asp) variant. (A) Patient 1: $34 \mathrm{yr}$-old male with left leg swelling and a capillary malformation of his posterior leg and buttock. (B) Significant progression of his disease at age $37 \mathrm{yr}$. (C) Axial T2-weighted fat-saturated magnetic resonance image of the left leg. Extensive reticular hyperintense signal within the overgrown subcutis. The posterior tibial vessels (arrowhead) are dilated with superficial enlarged medial veins (arrow). (D) Angiography shows a dilated posterior tibial artery with multiple enlarged, tortuous branches supplying the subcutaneous tissue of the medial aspect of the leg around the great saphenous vein. (E) Lymphoscintigram image $45 \mathrm{~min}$ following radiolabeled tracer injection into the feet demonstrates absence of flow to the inguinal nodes and dermal backflow confirming lymphedema. (F) Patient 2: 13-yr-old male with left leg overgrowth. (G) Enlargement of his affected extremity at age 22. (H) Magnetic resonance imaging (MRI) shows dilated vessels, subcutaneous microcystic lymphatic anomalies, and edema. (I) Angiogram exhibits arteriovenous connections. $(J)$ Lymphoscintigraphy illustrates lymphedema of the left leg (no inguinal node tracer uptake $45 \mathrm{~min}$ after injection).

\section{TECHNICAL ANALYSIS}

The resected specimens underwent targeted exome sequencing with OncoPanel (Goss et al. 2019) (Brigham and Women's Hospital Department of Pathology). The OncoPanel assay surveys exonic DNA sequences of 447 cancer genes and 191 regions across 60 genes for rearrangement detection. DNA is isolated from tissue containing at least $20 \%$ tumor nuclei and analyzed by massively parallel sequencing using a solution-phase Agilent SureSelect hybrid capture kit and an Illumina HiSeq 2500 sequencer. The specimen for Patient 1 generated 13,848,235 aligned, high-quality reads with a mean of 302 reads across all targeted exons and $98 \%$ of all exons having more than 30 reads. The specimen for Patient 2 generated $8,119,343$ aligned, high-quality reads with a mean of 233 reads across all targeted exons and $97 \%$ of all exons having more than 30 reads.

\section{RESULTS}

Both patient specimens contained a mosaic KRAS variant (NM_004985.5:c.35G > A; p.Gly12Asp) (Table 1). Variant allele fractions were 13\% (Patient 1) and 9\% (Patient 2). 
Table 1. Variant table

\begin{tabular}{ccccccc}
\hline Gene & Genomic location & HGVS cDNA & HGVS protein & Zygosity & Parent of origin & Variant interpretation \\
\hline KRAS & $\begin{array}{c}\text { Chr 12: 25245350 } \\
\text { (GRCh38) }\end{array}$ & $\begin{array}{c}\text { NM_004985.5: } \\
\text { c.35G }>\text { A }\end{array}$ & p.Gly12Asp & $\begin{array}{c}\text { Somatic } \\
\text { heterozygous }\end{array}$ & N/A & Pathogenic \\
\hline
\end{tabular}

Droplet digital polymerase chain reaction (PCR) confirmed the variant in the resected tissue of Patient 1 (Patient 2 was not tested) and did not identify the variant in the whole blood DNA of either subject. Testing for EPHB4 variants was not performed.

\section{DISCUSSION}

This report shows that KRAS is a locus for Parkes Weber syndrome. Similar to Parkes Weber syndrome caused by germline RASA1 and EPHB4 variants, the individuals had arteriovenous shunting and extremity overgrowth. In contrast, the patients exhibited lymphedema, lymphorrhea, repeated infections, lighter-colored capillary malformations, and significant enlargement of the affected extremity. The same somatic KRAS variant (NM_004985.5:c.35G > A; p.Gly12Asp) recently was reported in a 3-yr-old male with lower extremity overgrowth, arteriovenous fistulas, and capillary malformation; lymphatic dysfunction was not present (Schmidt et al. 2021).

Pathogenic KRAS variants are the most common cause for intracranial arteriovenous malformations (Nikolaev et al. 2018), and most extracranial arteriovenous malformations result from MAP2K1 variants (Couto et al. 2017). Extracranial arteriovenous malformations with KRAS variants are associated with intramuscular fast-flow vascular anomaly (Goss et al. 2019) as well as lesions resembling congenital hemangiomas (Sudduth et al. 2020). Because KRAS variants cause intramuscular fast-flow vascular anomaly, its association with Parkes Weber syndrome, which contains diffuse intramuscular arteriovenous fistulas, is consistent. The association of the KRAS variant with primary lymphedema also has precedent because lymphatic abnormalities can occur in KRAS-related cardiofaciocutaneous and Noonan syndromes (Schubbert et al. 2006; Morcaldi et al. 2015).

Somatic variants in KRAS also have been associated with encephalocraniocutaneous lipomatosis and Schimmelpenning syndrome (Groesser et al. 2012; McDonell et al. 2018). Patients with Schimmelpenning syndrome have an increased risk of vascular anomalies, including lymphatic malformations (Greene et al. 2007). Neither of the patients we describe in this report had clinical findings diagnostic for encephalocraniocutaneous lipomatosis or Schimmelpenning syndrome (e.g., nevus psiloliparus, choristomas, macrocephaly, nevus sebaceous, hypoplastic bones, ocular abnormalities).

This report confirms that Parkes Weber syndrome can be caused by a mosaic KRAS variant. Although Parkes Weber syndrome resulting from RASA1 or EPHB4 germline variants has an overlapping phenotype, KRAS-related Parkes Weber syndrome can also include lymphedema. Individuals with suspected Parkes Weber syndrome without RASA1 or EPHB4 germline variants should be tested for somatic KRAS variants, especially if they exhibit lymphatic malformations. Pharmacotherapy against KRAS or other targets in this pathway might prevent worsening extremity overgrowth.

\section{ADDITIONAL INFORMATION}

\section{Database Deposition and Access}

The generated data set has been deposited in the ClinVar database (https://www.ncbi.nlm .nih/gov/clinvar/) under accession number SCV001739511. 
Competing Interest Statement The authors have declared no competing interest.

Received June 26, 2021; accepted in revised form September 7, 2021.

\section{Ethics Statement}

The Committee on Clinical Investigation at Boston Children's Hospital approved this study. All procedures performed were in accordance with the ethical standards of the institutional and national research committee and with the 1964 Helsinki Declaration and its later amendments or comparable ethical standards.

\section{Author Contributions}

W.E. curated the data, administered the project, visualized and conceptualized the project, reviewed and edited the writing, and provided formal analysis, methodology, validation, and investigation; C.L.S., D.J.K., and P.J.S. curated the data, administered the project, visualized the project, administered the software, reviewed and edited the writing, and provided formal analysis, methodology, validation, and investigation; A.H.T. and S.J.F. visualized the project, reviewed and edited the writing, and provided resources, supervision, and validation; A.A. curated the data, administered the software, visualized the project, reviewed and edited the writing, and provided formal analysis, methodology, and validation; D.M.A. curated the data, administered the software, visualized the project, reviewed and edited the writing, established the methodology, and provided resources, supervision, and validation; and A.K.G. curated the data, administered the project, administered the software, visualized the project, wrote the original draft, reviewed and edited the writing, conceptualized the project, and provided formal analysis, funding acquisition, methodology, resources, supervision, validation, and investigation.

\section{Funding}

Research reported in this publication was supported by the Eunice Kennedy Shriver National Institute of Child Health \& Human Development of the National Institutes of Health under Award Number R01HD093735 (A.K.G.). W.E. was supported by Agency for Healthcare Research and Quality (AHRQ) grant number T32HS000063 as part of the Harvard Pediatric Health Services Research Fellowship Program. The content is solely the responsibility of the authors and does not necessarily represent the official views of the National Institutes of Health.

\section{REFERENCES}

Amyere M, Revencu N, Helaers R, Pairet E, Baselga E, Cordisco M, Chung W, Dubois J, Lacour J, Martorell L, et al. 2017. Germline loss-of-function mutations in EPHB4 cause a second form of capillary malformationarteriovenous malformation (CM-AVM2) deregulating RAS-MAPK signaling. Circulation 136: 1037-1048. doi:10.1161/CIRCULATIONAHA.116.026886

Couto JA, Huang AY, Konczyk DJ, Goss JA, Fishman SJ, Mulliken JB, Warman ML, Greene AK. 2017. Somatic MAP2K1 mutations are associated with extracranial arteriovenous malformation. Am J Hum Genet 100: 546-554. doi:10.1016/j.ajhg.2017.01.018

Flores Daboub JA, Grimmer JF, Frigerio A, Wooderchak-Donahue W, Arnold R, Szymanski J, Longo N, BayrakToydemir P. 2020. Parkes Weber syndrome associated with two somatic pathogenic variants in RASA1. Cold Spring Harb Mol Case Stud 6: a005256. doi:10.1101/mcs.a005256

Goss JA, Konczyk DJ, Smits PJ, Kozakewich HPW, Alomari Al, Al-Ibraheemi A, Taghinia AH, Dickie BH, Adams DM, Fishman SJ, et al. 2019. Intramuscular fast-flow vascular anomaly contains somatic MAP2K1 and KRAS mutations. Angiogenesis 22: 547-552. doi:10.1007/s10456-019-09678-w

Greene AK, Rogers GF, Mulliken JB. 2007. Schimmelpenning syndrome: an association with vascular anomalies. Cleft Palate Craniofac J 44: 208-215. doi:10.1597/06-025.1

Groesser L, Herschberger E, Ruetten A, Ruivenkamp C, Lopriore E, Zutt M, Langmann T, Singer S, Klingseisen L, Schneider-Brachert W, et al. 2012. Postzygotic HRAS and KRAS mutations cause nevus sebaceous and Schimmelpenning syndrome. Nat Genet 44: 783-787. doi:10.1038/ng.2316 
McDonell LM, Leung GKC, Daoud H, Ip J, Chim S, Luk HM, Lan L, Boycott KM, Chung BHY. 2018. Mosaic KRAS mutation in a patient with encephalocraniocutaneous lipomatosis and renovascular hypertension. Am J Med Genet A 176: 2523-2527. doi:10.1002/ajmg.a.40349

Morcaldi G, Bellini T, Rossi C, Maghnie M, Boccardo F, Bonioli E, Bellini C. 2015. Lymphodysplasia and KRAS mutation: a case report and literature review. Lymphology 48: 121-127.

Nikolaev SI, Vetiska S, Bonilla X, Boudreau E, Jauhiainen S, Rezai Jahromi B, Khyzha N, DiStefano PV, Suutarinen S, Kiehl TR, et al. 2018. Somatic activating KRAS mutations in arteriovenous malformations of the brain. N Engl J Med 378: 250-261. doi:10.1056/NEJMoa1709449

Revencu N, Boon LM, Mulliken JB, Enjolras O, Cordisco MR, Burrows PE, Clapuyt P, Hammer F, Dubois J, Baselga $E$, et al. 2008. Parkes Weber syndrome, vein of Galen aneurysmal malformation, and other fastflow vascular anomalies are caused by RASA1 mutations. Hum Mutat 29: 959-965. doi:10.1002/humu .20746

Schmidt VF, Wieland I, Wohlgemuth WA, Ricke J, Wildgruber M, Zenker M. 2021. Mosaic RASopathy due to $K R A S$ variant $\mathrm{G12D}$ with segmental overgrowth and associated peripheral vascular malformations. Am J Med Genet A 38: 331-336.

Schubbert S, Zenker M, Rowe SL, Böll S, Klein C, Bollag G, van der Burgt I, Musante L, Kalscheuer V, Wehner LE, et al. 2006. Germline KRAS mutations cause Noonan syndrome. Nat Genet 38: 331-336. doi:10.1038/ ng1748

Sudduth CL, McGuire AM, Smits PJ, Konczyk DJ, Al-lbraheemi A, Fishman SJ, Greene AK. 2020. Arteriovenous malformation phenotype resembling congenital hemangioma contains KRAS mutations. Clin Genet 98: 595-597. doi:10.1111/cge.13833 


\section{COLD SPRING HARBOR Molecular Case Studies}

\section{Parkes Weber syndrome with lymphedema caused by a somatic KRAS variant}

Whitney Eng, Christopher L. Sudduth, Dennis J. Konczyk, et al.

Cold Spring Harb Mol Case Stud 2021, 7: a006118 originally published online October 4, 2021 Access the most recent version at doi: $10.1101 / \mathrm{mcs}$.a006118

References This article cites 13 articles, 2 of which can be accessed free at: http://molecularcasestudies.cshlp.org/content/7/6/a006118.full.html\#ref-list-1

License This article is distributed under the terms of the Creative Commons Attribution-NonCommercial License, which permits reuse and redistribution, except for commercial purposes, provided that the original author and source are credited.

Email Alerting Receive free email alerts when new articles cite this article - sign up in the box at the Service top right corner of the article or click here. 